\title{
De novo mutations in FBRSL1 cause a novel recognizable malformation and intellectual disability syndrome
}

\author{
Roser Ufartes ${ }^{1} \cdot$ Hanna Berger ${ }^{2} \cdot$ Katharina Till $^{2} \cdot$ Gabriela Salinas $^{3} \cdot$ Marc Sturm $^{4}$ - Janine Altmüller ${ }^{5}$. \\ Peter Nürnberg ${ }^{5,6} \cdot$ Holger Thiele $^{5} \cdot$ Rudolf Funke $^{7} \cdot$ Neophytos Apeshiotis $^{8} \cdot$ Hendrik Langen $^{9} \cdot$ Bernd Wollnik $^{1,10}$. \\ Annette Borchers ${ }^{2,11}$ [D $\cdot$ Silke Pauli ${ }^{1}$ (D)
}

Received: 18 February 2020 / Accepted: 2 May 2020 / Published online: 18 May 2020

(c) The Author(s) 2020

\begin{abstract}
We report truncating de novo variants in specific exons of FBRSL1 in three unrelated children with an overlapping syndromic phenotype with respiratory insufficiency, postnatal growth restriction, microcephaly, global developmental delay and other malformations. The function of FBRSL1 is largely unknown. Interestingly, mutations in the FBRSL1 paralogue AUTS2 lead to an intellectual disability syndrome (AUTS2 syndrome). We determined human FBRSL1 transcripts and describe proteincoding forms by Western blot analysis as well as the cellular localization by immunocytochemistry stainings. All detected mutations affect the two short $\mathrm{N}$-terminal isoforms, which show a ubiquitous expression in fetal tissues. Next, we performed a Fbrsl1 knockdown in Xenopus laevis embryos to explore the role of Fbrsl1 during development and detected craniofacial abnormalities and a disturbance in neurite outgrowth. The aberrant phenotype in Xenopus laevis embryos could be rescued with a human $\mathrm{N}$-terminal isoform, while the long isoform and the N-terminal isoform containing the mutation p.Gln163* isolated from a patient could not rescue the craniofacial defects caused by Fbrsl1 depletion. Based on these data, we propose that the disruption of the validated N-terminal isoforms of FBRSL1 at critical timepoints during embryogenesis leads to a hitherto undescribed complex neurodevelopmental syndrome.
\end{abstract}

\section{Introduction}

In two unrelated children with a nearly identical clinical phenotype we performed trio-exome sequencing to uncover the underlying cause of a hitherto undiagnosed congenital malformation syndrome. In both affected children, we detected a de novo truncating variant in FBRSL1. Single exome sequencing and "reverse phenotyping" revealed a third patient having a truncating FBRSL1 mutation. The function of FBRSL1 is largely unknown and so

Roser Ufartes and Hanna Berger have contributed equally to this work.

Electronic supplementary material The online version of this article (https://doi.org/10.1007/s00439-020-02175-x) contains supplementary material, which is available to authorized users.

Annette Borchers

borchers@uni-marburg.de

Silke Pauli

spauli@gwdg.de

Extended author information available on the last page of the article far this gene has not been associated with any syndromic phenotype. Interestingly, mutations in the FBRSL1 paralogue AUTS2 (NG_034133.1, activator of transcription and developmental regulator) were first described in 2013 as causative of an intellectual disability syndrome with microcephaly and, in some cases, additional features like heart defects and contractures (AUTS2 syndrome, OMIM 615834) (Beunders et al. 2013). Our patients presented with features of the AUTS2 syndrome and additional symptoms, suggesting that mutations in FBRSL1 produce a more complex phenotype than mutations in the paralogue AUTS2.

AUTS2 and FBRSL1 are components of the Polycomb subcomplexes PRC1.3 and PRC1.5 (Gao et al. 2014; Scelfo et al. 2015; Chittock et al. 2017). Polycomb complexes fulfill an important function during embryonic development by inactivating numerous target genes (e.g., HOX genes and transcription factors) at specific developmental timepoints (Müller and Verrijzer 2009; Simon and Kingston 2013; Schuettengruber et al. 2017). Polycomb repressive complexes are divided into different subgroups according to their function and additional complex partners ( $\mathrm{Gao}$ 
et al. 2012). While PRC1 complexes exert their repressive function by chromatin compaction and H2AK119 monoubiquitination via the E3 ligases RING1A or RING1B, PRC2 complexes act by catalyzing methylation of the repressive histone mark H3K27 (H3K27me3) (Simon and Kingston 2013).

Interestingly, binding of AUTS2 to the respective polycomb complex (PRC1.3 or PRC1.5) inhibits the repressive function; the AUTS2-PRC complex thus acts as a transcriptional activator. This is achieved by the recruitment of histone acetyltransferase p300, a known transcriptional coactivator, and casein kinase 2 , which inhibits the repressive PRC1 function (Gao et al. 2014; Hori and Hoshino 2017). It is unknown whether an FBRSL1-PRC complex acts in a repressive or activating manner.

Mutations in members of the PRC1 and PRC2 complex as well as in trithorax group proteins, counterparts of polycomb complexes, underlie numerous malformation and intellectual disability syndromes often caused by de novo mutations (Ng et al. 2004, 2010; Vissers et al. 2004; Lederer et al. 2012; Awad et al. 2013; Deevy and Bracken 2019). Therefore, it is likely that further uncharacterized PRC-associated proteins, like FBRSL1, are also associated with a malformation syndrome.

Here, we report the clinical presentation and molecular etiology of a novel syndrome and the functional analysis of FBRSL1, the involved gene.

\section{Material and methods}

\section{Variant identification (whole-exome sequencing)}

Whole-exome sequencing was performed on a blood DNA sample of patient 3 using Agilent SureSelect Human All Exon V6 r2 kit on an Illumina HiSeq4000 sequencer. Trio exome sequencing was performed on blood DNA samples of patients 1 and 2 and their parents using Agilent's SureSelectXT Human All Exon V5 Enrichment method. Trio analysis of samples of patient 1 and 2 was performed using the megSAP pipeline developed at the medical genetics department in Tübingen (https://github.com/imgag/megSAP). The exome data of patient 3 were analyzed using the "Varbank" pipeline of the Cologne Center for Genomics (CCG) with following filter criteria: coverage of $>6$ reads, quality score of $>10$, allele frequency of $\geq 25 \%$, and a minor allele frequency (MAF) of $<0.1 \%$ in the 1000 Genomes database and the Exome Variant Server (EVS; NHLBI Exome Sequencing Project). In patient 3, the results were analyzed by the multidisciplinary NGS data analysis team [Mutation Mining (MM)-Team] of the Institute of Human Genetics, University Medical Center Göttingen.

\section{Transcript identification/RNA studies}

To investigate the expression of different transcripts, RNA from lymphocytes was isolated and two $\mu \mathrm{g}$ RNA was reverse transcribed using Random Primers (SuperScript, Invitrogen). The different transcripts were amplified by PCR using specific primer and the Q $5^{\circledR}$ High-Fidelity DNA Polymerase (NEB). Sanger sequencing was performed to confirm the correct sequence. Afterwards, three transcripts were analyzed in different organs using a human adult and fetal cDNA panel from Clontech.

Sequencing of RNA-seq samples was conducted at the NGS Integrative Genomics Core Unit, University Medical Center Göttingen. Sequence images were transformed with Illumina software BaseCaller to BCL files, which was demultiplexed to fastq files with bcl2fastq v2.17.1.14. The sequencing quality was asserted using FastQC (Andrews 2014). FastQC A Quality Control tool for High Throughput Sequence Data. (https://www.bioinformatics.babra ham.ac.uk/projects/fastqc/) (version 0.11.5). Sequences were aligned to the reference genome Homo sapiens (hg38 version 89, https://www.ensembl.org/Homo_sapiens/Info/ Index) using the STAR aligner (Dobin et al. 2013) (version 2.5.2a) allowing for 2 mismatches within 50 bases. Subsequently, read counting was performed using featureCounts (Liao et al. 2014) (version 1.5.0-p1). Reads mapped to the FBRSL1 gene were visualized using Integrated Genome Viewer (IGV) version 2.8.2.

\section{Plasmid preparation}

The full-length human wild-type FBRSL1 isoform 1 (NCBI, NM_001142641.1) and 3.1 (NCBI, XM_005266181.4) in the vector pcDNA3.1 (+)-N-HA were synthetized by GenScript. Isoform 3.2 (ENSEMBL, ENST00000542061.2,) was amplified by PCR using DNA from human lymphocytes. The PCR product was cloned into the pCMV-HA vector (Clontech) by using the In-Fusion ${ }^{\circledR}$ HD Cloning Kit (Clontech) according to the manufacturer's protocol. To introduce the nonsense mutation, c. 487C > T (p.Gln163*), site-directed mutagenesis PCR was performed by using the QuikChange II XL Site-Directed Mutagenesis Kit (Agilent) according to the manufacturer's protocol.

Sanger sequencing was performed for each plasmid to confirm the correct sequence. Sequences of used primers can be sent on request. 


\section{Western blot analysis}

Total lysate was isolated from HEK293 cells using modified RIPA Buffer. $30 \mu \mathrm{g}$ protein were separated by a $4-12 \%$ NuPAGE Bis-Tris Gel (Invitrogen) and transferred to a Protran nitrocellulose membrane $(0.45 \mu \mathrm{m})$ (SigmaAldrich) using a Tank system (Bio-Rad) at $250 \mathrm{~mA}$ for 60 min at $4{ }^{\circ} \mathrm{C}$. After blocking the membrane with $5 \%$ milk/TBST (Carl Roth) for $60 \mathrm{~min}$, the membrane was incubated with appropriate primary antibodies overnight at $4{ }^{\circ} \mathrm{C}$. Rat anti-HA (11867431001, Sigma-Aldrich) was used at a dilution of 1:2000 in 2\% milk/TBST. Rabbit anti-FBRSL1 (HPA049880, Sigma-Aldrich) was used at a dilution of 1:500 in $2 \%$ milk/TBST. After washing, the membrane was incubated with the following secondary antibodies: anti-rat IgG peroxidase secondary antibody (Sigma-Aldrich) at a dilution of $1: 10,000$ in $2 \%$ milk/ TBST, goat IgG anti-rabbit (H+L)-HRPO (Dianova) at a dilution of $1: 10,000$ in $2 \%$ milk/TBST. The membrane was washed and Immobilon Western Chemiluminescent HRP Substrate (Merck Millipore) was applied on the membrane. Bands were detected with the Azur detecting system.

\section{Cell culture and transient transfection}

HEK293 cells were cultured in Dulbecco's modified Eagle's medium (DMEM) (PAN-Biotech), supplemented with 10\% fetal bovine serum (FBS) (PAN-Biotech), $1 \times$ MEM NonEssential Amino Acids (NEAA) (Thermo Fisher Scientific) and $1 \%$ penicillin/streptomycin (Thermo Fisher Scientific). For transfection, $5 \times 10^{6}$ HEK293 cells were plated into T75 culture flasks (Greiner Bio-One). $24 \mathrm{~h}$ after plating the cells, cells were transfected with $10-\mu \mathrm{g}$ plasmid using jetPrime (Polyplus) according to the manufacturer's instructions. Medium was changed four hours after transfection. $24 \mathrm{~h}$ after transfection, cells were harvested for further analysis. For immunocytochemistry experiments, $2 \times 10^{5}$ HEK293 cells were plated into a 12-well plate on $12 \mathrm{~mm}$ cover slips (YX03.1, Roth). Cover slips were coated with $0.1 \%$ polylysine (P2636, Sigma-Aldrich) $4 \mathrm{~h}$ before plating the cells. $24 \mathrm{~h}$ after plating, the cells were fixed with $4 \%$ paraformaldehyde (PFA) for $10 \mathrm{~min}$ at room temperature (RT).

\section{Immunocytochemistry}

Fixed cells were permeabilized with $0.5 \%$ Triton X-100 in PBS for 10 min, washed twice with $0,1 \%$ Tween in PBS (PBT) and blocked with 3\% BSA in PBT for $30 \mathrm{~min}$ at RT. Afterwards primary antibodies in blocking buffer (1:100 anti-FBRSL1-N-terminal, Sigma-Aldrich, 1:100 antiFBRSL1-C-terminal, Sigma-Aldrich, 1:2000 mouse monoclonal anti- $\alpha$-tubulin, Sigma-Aldrich) were used overnight at $4{ }^{\circ} \mathrm{C}$. After incubation, cells were washed with PBT and incubated for $1 \mathrm{~h}$ at RT with secondary antibodies (1:600 goat anti-rabbit $\operatorname{IgG}(\mathrm{H}+\mathrm{L})$-Alexa Fluor 488, 1:600 goat anti-mouse $\operatorname{IgG}(\mathrm{H}+\mathrm{L})$-Alexa Fluor 546; Invitrogen). Subsequently, cells were washed twice and mounted using Fluoroshield ${ }^{\mathrm{TM}}$ with DAPI (Merck Millipore). Immunofluorescent images were acquired using the Olympus BX60 microscope with $\times 600$ magnification, and an additional software magnification of 3, 6, 9 and 12. All images were processed with FIJI (an image-processing package based on ImageJ). All experiments were performed three times.

\section{Studies in Xenopus laevis}

\section{Xenopus microinjection}

Xenopus laevis embryos were obtained and cultured using standard protocols and staged according to the normal table of Nieuwkoop and Faber (Nieuwkoop and Faber 1956). All procedures were performed according to the German Animal Use and Care Act (Tierschutzgesetz) and approved by the German state administration Hesse (Regierungspräsidium Giessen). For phenotypical analysis, Xenopus embryos were injected in one blastomere at the two-cell stage and for RT-PCR at the one-cell stage. Capped sense mRNA for microinjection was synthetized using the mMessage mMachine ${ }^{\mathrm{TM}}$ SP6 Transcription Kit (Invitrogen ${ }^{\mathrm{TM}}$ ) from the following plasmids: lacZ (Smith and Harland 1991) and mGFP (Moriyoshi et al. 1996). The following Morpholino Oligonucleotides (MO) were used for microinjections: Standard control morpholino (Co MO, 5'-CCTCTTACCTCAGTTACAATTTATA-3', Gene Tools, LLC) and $f b r s l l$ E1/I1 splice MO (fbrsll MO, 5'- ATA ACTCTCTCTTACCTCTAAGGCT-3', Gene Tools, LLC). For rescue experiments plasmid microinjection using the human FBRSL1 transcript variants, FBRSL1 isoform 1, FBRSL1 isoform 3.1 and FBRSL1 isoform 3.1-p.Gln163* were performed.

\section{Phenotypical characterization of Xenopus laevis embryos}

For phenotypical characterization of the craniofacial structures, $100 \mathrm{pg}$ lacZ mRNA were co-injected as lineage tracer. Embryos were fixed in MEMFA (3.7\% formaldehyde, $0.1 \mathrm{M}$ MOPS, 2 mM EGTA, $2 \mathrm{mM} \mathrm{MgSO}_{4}$ ) and the injected side was visualized by $\mathrm{X}$-gal staining. For phenotypical documentation of craniofacial defects, a Leica M165 FC stereo microscope with a DFC450C Camera was used.

\section{Whole-mount immunofluorescence staining of Xenopus laevis embryos}

For whole-mount immunofluorescence staining, the embryos were co-injected with $50 \mathrm{pg} m G F P$ mRNA as a lineage 
tracer. Embryos were fixed in Dent's fixative (20\% DMSO, $80 \%$ methanol), washed twice in PBS, and subsequently photobleached in $2 \% \mathrm{H}_{2} \mathrm{O}_{2}$ in PBS under a light source until the embryos lost their pigmentation. After photobleaching, the embryos were washed twice in PBS-TD (1\% Triton X-100, $1 \%$ DMSO, $1 \times$ PBS) and blocked for two hours in blocking buffer $(0.1 \mathrm{M}$ glycine, $2 \%$ nonfat dried milk, 5\% FBS in PBS-TD) at room temperature. Afterwards, the embryos were rinsed in PBS-TD and treated with $1 \mathrm{mg} / \mathrm{ml}$ bovine testicular hyaluronidase (Sigma Aldrich) in $50 \mathrm{mM}$ sodium acetate buffer ( $\mathrm{pH}$ 6) for $45 \mathrm{~min}$ at RT. The samples were washed in PBS-TD, blocked again for 30 min in blocking solution and incubated with the primary antibody anti-Collagen Type II (DSHB, II-II6B3) or anti-Ncam (DSHB, 4d) diluted 1:50 in blocking buffer overnight at $4{ }^{\circ} \mathrm{C}$. The following day, six wash steps in PBS-TD of $30 \mathrm{~min}$ to $1 \mathrm{~h}$ each were performed following incubation with the secondary antibody Alexa Fluor ${ }^{\circledR} 594$ Goat anti-Mouse (Invitrogen ${ }^{\mathrm{TM}}$, A-11005, diluted 1:400 in blocking buffer) overnight at $4{ }^{\circ} \mathrm{C}$. After overnight incubation, again six wash steps in PBSTD of $30 \mathrm{~min}$ to $1 \mathrm{~h}$ each were performed and the embryos were subsequently re-fixed in Dent's fixative overnight at $4{ }^{\circ} \mathrm{C}$. Before imaging, embryos were washed twice in $100 \%$ ethanol and incubated in Benzyl-alcohol/Benzyl-benzoate (BA/BB, 1:2) in glass dishes for $10 \mathrm{~min}$. Imaging of the stained cartilage was performed in fresh BA/BB in glass dishes using a Leica M165 FC stereo microscope with a DFC450C Camera. Brain and cartilage phenotypes were quantified by measuring the area of both brain hemispheres or the cartilage (ceratohyal cartilage and branchial arches), respectively, using the polygon function of ImageJ. The relative surface area between control side and Morpholino injected side was calculated by setting the control side to $100 \%$. The embryos were classified as having defects, if the brain or the cartilage area of the injected side was reduced by at least $15 \%$ compared to the control side.

\section{Statistical analysis}

To analyze the significance of the statistical data, a twotailed unpaired Student's $t$-test and a one-way ANOVA test were applied with the indicated $p$ values: $* p \leq 0.05$, ${ }^{* *} p \leq 0.01, * * * p \leq 0.001$.

\section{RT-PCR (Xenopus laevis)}

To verify the fbrsll splice-blocking effect of the fbrsll Morpholino total RNA was isolated from stage 30 embryos injected with $10 \mathrm{ng}$ Co MO or $10 \mathrm{ng}$ fbrsll MO. To analyze the temporal expression pattern of fbrsll in Xenopus embryos, RNA was isolated from oocytes and embryos of different developmental stages. Five embryos per condition were used for RNA isolation using the GE Healthcare Illustra RNAspin Mini Isolation Kit according to the manufacturer's instructions. $2 \mu \mathrm{g}$ of the isolated RNA served as template for cDNA synthesis and was mixed with $0.2 \mu \mathrm{g}$ Random Hexamer Primer (Thermo Scientific) in a volume of $13.5 \mu \mathrm{l}$ and incubated at $65{ }^{\circ} \mathrm{C}$ at $5 \mathrm{~min}$. After incubation, $1 \mathrm{mM}$ dNTP Mix (Thermo Scientific), 20 units MuLV Reverse transcriptase (Thermo Scientific), $5 \times$ Reaction Buffer (Thermo Scientific) and 20 units RNaseOUT (Invitrogen ${ }^{\mathrm{TM}}$ ) and bidest $\mathrm{H}_{2} \mathrm{O}$ were added to a final volume of $20 \mu \mathrm{l}$. The reaction was incubated for $10 \mathrm{~min}$ at $25^{\circ} \mathrm{C}$ following incubation for $1 \mathrm{~h}$ at $42{ }^{\circ} \mathrm{C}$. The following primers were used to verify the fbrsll Morpholino: forward primer (5'-ATGGATATTAAAACCAAACAACCAAGCAGG $\left.-3^{\prime}\right)$ and reverse primer (5'-ACAGAGGGTAAGGGGGAA GTT-3'). To analyze the temporal $f b r s l l$ expression pattern the forward primer (5'-ATGGATATTAAAACCAAACAA CCAAGCAGG-3') and the reverse primer (5'-GTGAGA CGTGGAGGAGCTGG-3') were used to amplify a 942 bp fbrsll fragment. As control histone $\mathrm{H} 4$ was amplified using the forward primer (5'-CGGGATAACATTCAGGGTATC ACT-3') and the reverse primer (5'-ATCCATGGCGGTAAC TGTCTTCCT- $3^{\prime}$ ). PCR products were separated on an agarose gel and detected using the Odyssey ${ }^{\circledR}$ Fc Imaging System (LI-COR Bioscience).

\section{Results}

\section{Identification of FBRSL1 variants in three patients with a recognizable malformation syndrome}

Two unrelated children presented with respiratory insufficiency, feeding difficulties, postnatal growth restriction and microcephaly, global developmental delay, no active speech, contractures, heart defects, cleft palate, facial dysmorphism and distinctive skin creases in the first year of life. The skin phenotype was most pronounced immediately after birth and regressed in both children with increasing age. In contrast to the skin phenotype observed in children affected by the congenital symmetric circumferential skin creases syndrome (CSCSC1, OMIM 156,610; and CSCSC2, OMIM 616,734), the back was preferentially affected in our patients and not the arms and legs (Fig. 1). The clinical presentation could not be assigned to a known syndrome, although there are 
Fig. 1 Clinical representation of the three patients. A Patient 1 at the age of six months: a part of the face $\mathbf{b}$ side view showing a pronounced neck fold, a flat back of the head and a dysmorphic auricle c side view of the right leg with wrinkles and $\mathbf{d}$ side view with a view of the back area with pronounced skin fold formation. B Patient 2 at the age of five months: a front view showing deep-set eyes, a round face and temporal indentations; $\mathbf{b}$ side view, which also shows a flat back of the head and a slightly dysplastic auricle. Due to the fixation of the tracheostoma, the pronounced neck fold is not visible; $\mathbf{c}$ view of the back with wrinkles; $\mathbf{d}$ view of the back of patient 2 at the age of two and a half years. A remarkable regression of the skin folds was observed. C Patient 1 at the age of 6 years and 7 months: $\mathbf{a}$ front-view and $\mathbf{b}$ side-view showing dysmorphic features. c Contractures on both hands and fingers are shown $(\mathbf{d}, \mathbf{e})$ view of the teeth. D front-view (a) and side-view (b) of patient 3 at the age of 12 years and 6 months. $\mathbf{c}, \mathbf{d}$ facial appearance of patient 3 at the age of 14 years and 8 months. Contractures of both hands and fingers are observed, as well as wide-spaced teeth
A

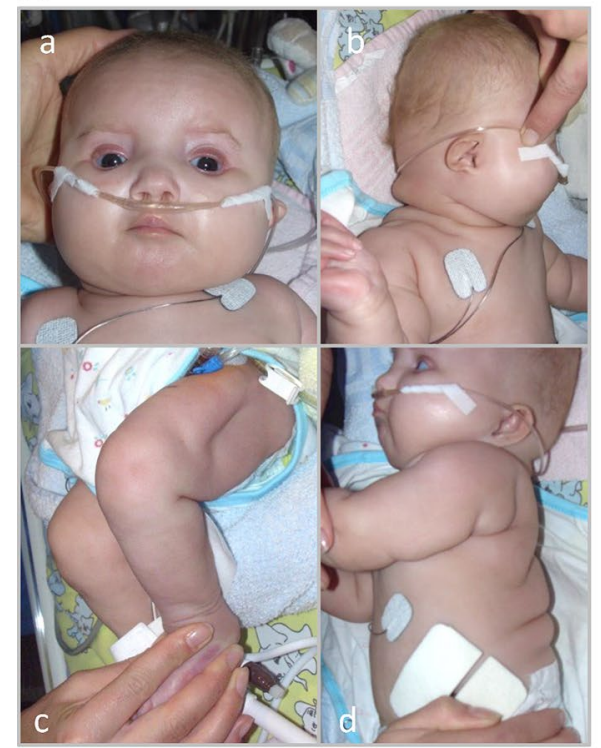

C

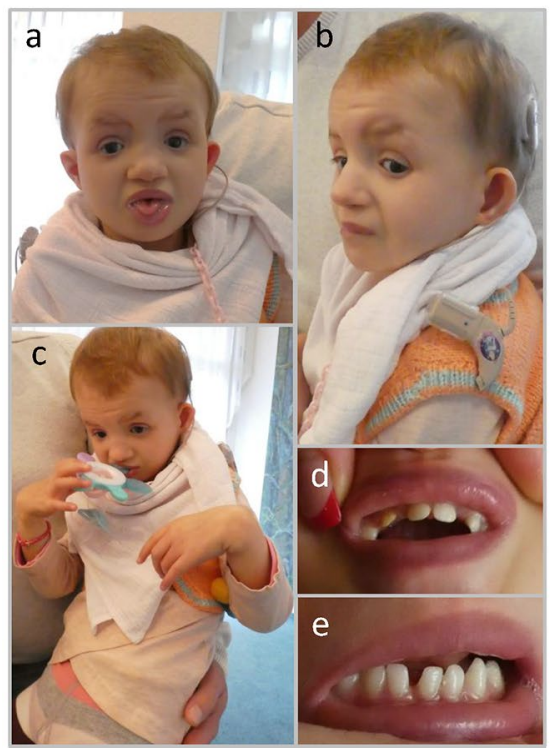

B

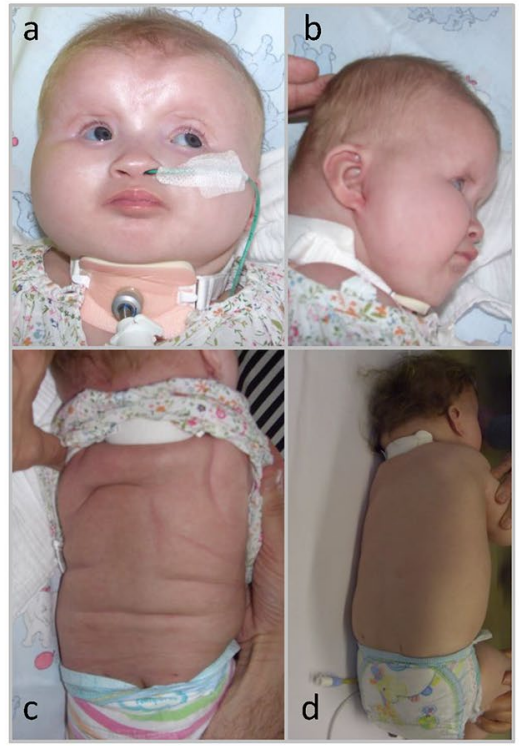

D

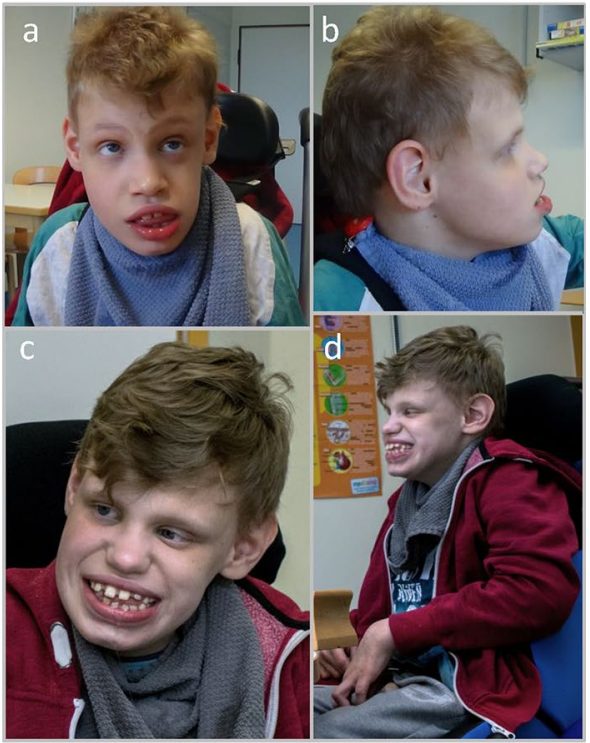

overlapping features to CSCSC1, CSCSC2 and AUTS2 syndrome (AUTS2 syndrome, OMIM 615,834).

We performed trio-exome sequencing to uncover the underlying cause. In both affected children, we excluded the presence of pathogenic variants in the genes TUBB and $M A P R E 2$ causing CSCSC 1 and CSCSC2, respectively, and mutations in AUTS2. However, a de novo truncating variant in FBRSL1, an uncharacterized AUTS2 paralogue, was identified in both children. The clinical findings in comparison to the published phenotype in AUTS2 syndrome patients are summarized in Table 1.

In patient 1 we identified in a heterozygous state the de novo mutation c.487C > T (12:133,085,942; GRCh37/hg19) in FBRSL1, leading to a premature stop codon (p.Gln163*).
Sanger sequencing confirmed the mutation in the child and the wild-type sequence of the corresponding region in both unaffected parents. In patient 2, no pathogenic change in the annotated and validated FBRSL1 transcript (NM_001142641.2) was initially detected. Since the child's clinical presentation was almost identical to that of patient 1 , we manually inspected putative intronic regions of the FBRSL1 gene, for which partial reads could be generated by Agilent's SureSelectXT Human All Exon V5 Enrichment method. For the region 12:133,085,800-133,085,880 (GRCh37/hg19), two reads were obtained in patient 2, each showing a 23-bp deletion (12:133,085,843-133,085,866; GRCh37/hg19), while in the parents only one read without deletion was observed (see Suppl. Figure 1A). To exclude 
Table 1 Summary of the observed clinical findings in comparison to the published phenotype in AUTS2 syndrome patients

\begin{tabular}{|c|c|c|c|c|}
\hline \multirow[t]{2}{*}{ Clinical description (HPO term) } & \multicolumn{3}{|c|}{ FBRSL1 mutations } & \multirow{2}{*}{$\begin{array}{l}\text { AUTS2 syndrome } \\
\text { Beunders et al. (2015), (2016) }\end{array}$} \\
\hline & $\begin{array}{l}\text { Patient } 1 \\
\text { c. } 487 \mathrm{C}>\mathrm{T} \text {, } \\
\text { p.Gln } 163^{*} ; \\
\text { de novo }\end{array}$ & $\begin{array}{l}\text { Patient } 2 \\
\text { c.581_603del; } \\
\text { de novo }\end{array}$ & $\begin{array}{l}\text { Patient } 3 \\
\text { c. } 332 \mathrm{G}>\mathrm{A} \text {; } \\
\text { p.Trp111*; } \\
\text { n.a }\end{array}$ & \\
\hline $\begin{array}{l}\text { Intellectual disability (HP:0001249) and/or global } \\
\text { development delay (HP:0001263) }\end{array}$ & + & + & + & + \\
\hline $\begin{array}{l}\text { Delayed speech and language development } \\
\text { (HP:0000750) }\end{array}$ & + & + & + & + \\
\hline Autistic behavior (HP:0000729) & + & + & + & + \\
\hline Microcephaly (HP:0000252) & + & + & + & + \\
\hline Swallowing difficulty (HP:0002015) & + & + & + & + \\
\hline Postnatal growth retardation (HP:0008897) & + & + & + & + \\
\hline Abnormality of the skeletal system (HP:0000924) & + & + & + & + \\
\hline Camptodactyly/contractures (HP:0001371) & + & + & + & + \\
\hline Heart defect (HP:0001627) & ASD/PDA & ASD/VSD & - & Atrial septum defect (ASD) \\
\hline Cleft palate (HP:0000175) & + & + & - & - \\
\hline $\begin{array}{l}\text { Respiratory failure (HP:0002878) with ventilation } \\
\text { therapy }\end{array}$ & + & + & + & - \\
\hline Asplenia (HP:0001746) & - & + & - & - \\
\hline Abnormality of the anus (HP:0004378) & + & - & - & - \\
\hline hearing impairment (HP:0000365) & + & + & - & - \\
\hline Abnormality of the skin (HP:0000951) skin creases & + & + & - & - \\
\hline Facial dysmorphism (HP:0001999) & + & + & + & - \\
\hline
\end{tabular}

n.a. father not available for testing, $A S D$ atrial septal defect, VSD ventricular septal defect, $P D A$ persistent ductus arteriosus botalli, $H P O$ human phenotype ontology

the 23-bp deletion as an artifact of a poorly covered region, we used Sanger sequencing on genomic DNA of patient 2 and her parents. This confirmed a heterozygous state of the 23-bp deletion in the affected child and a wild-type status of this gene region in the healthy parents (Suppl. Figure 1B, C).

To date, 15 hypothetical transcripts are listed for human FBRSL1 in NCBI. For AUTS2, the FBRSL1 paralogue, a long transcript and shorter $\mathrm{N}$ - and $\mathrm{C}$-terminal transcripts were validated. Therefore, it is conceivable that for FBRSL1 also shorter $\mathrm{N}$ - and $\mathrm{C}$-terminal transcripts exist like it is already known for the murine fbrsl1. The de novo 23-bp deletion would affect exon 3 of a hypothetical alternative $\mathrm{N}$-terminal transcript (XM_005266181.4), leading to a frameshift and premature stop codon (c.581_603del).

A third patient with a truncating FBRSL1 mutation (c.332 G > A; p.Trp111*; 12:133,085,787; GRCh37/hg 19) was identified by single exome sequencing and reverse phenotyping. The mutation was not detected in the healthy mother of patient 3. The father was not available for genetic testing.

Neither of the three identified variants is listed in the gno$\mathrm{mAD}$ database or Exome Aggregation Consortium (ExAC) (Lek et al. 2016). RNA- analysis revealed in all three children in comparison to the healthy parents in case 1 and 2 and the healthy mother in case 3 that the truncating variants escaped the mechanism of nonsense mediated mRNA decay (NMD) (Suppl. Figure 2).

\section{FBRSL1 consists of different isoforms and all three detected mutations affect short $\mathrm{N}$-terminal isoforms}

As the FBRSL1 transcript variants have only insufficiently been described, we subsequently performed RT-PCR analyses on cDNA isolated from control lymphocytes and Western blot analysis using protein isolated from HEK293 cells to identify and validate protein-encoding isoforms. By RTPCR we confirmed the existence of the hypothetical transcript XM_005266181.4 (NCBI). Compared to the validated long variant (NM_001142641.2, isoform 1, NCBI), this shorter isoform contains exons 1 and 2 and included an alternative exon 3 with a stop codon (isoform 3.1). In addition to this version 3.1, we also observed a variant consisting only of exon 2 and the alternative exon 3, using an in-frame ATG in exon 2 (isoform 3.2). This variant differs in the $5^{\prime} \mathrm{UTR}$ region and was annotated as a hypothetical transcript (ENST00000542061.2, ENSEMBL) (Fig. 2).

For validation of the detected 23-bp deletion on transcript level, we performed RT-PCR analysis on cDNA isolated from lymphocytes from patient 2 and her parents. This 
gDNA
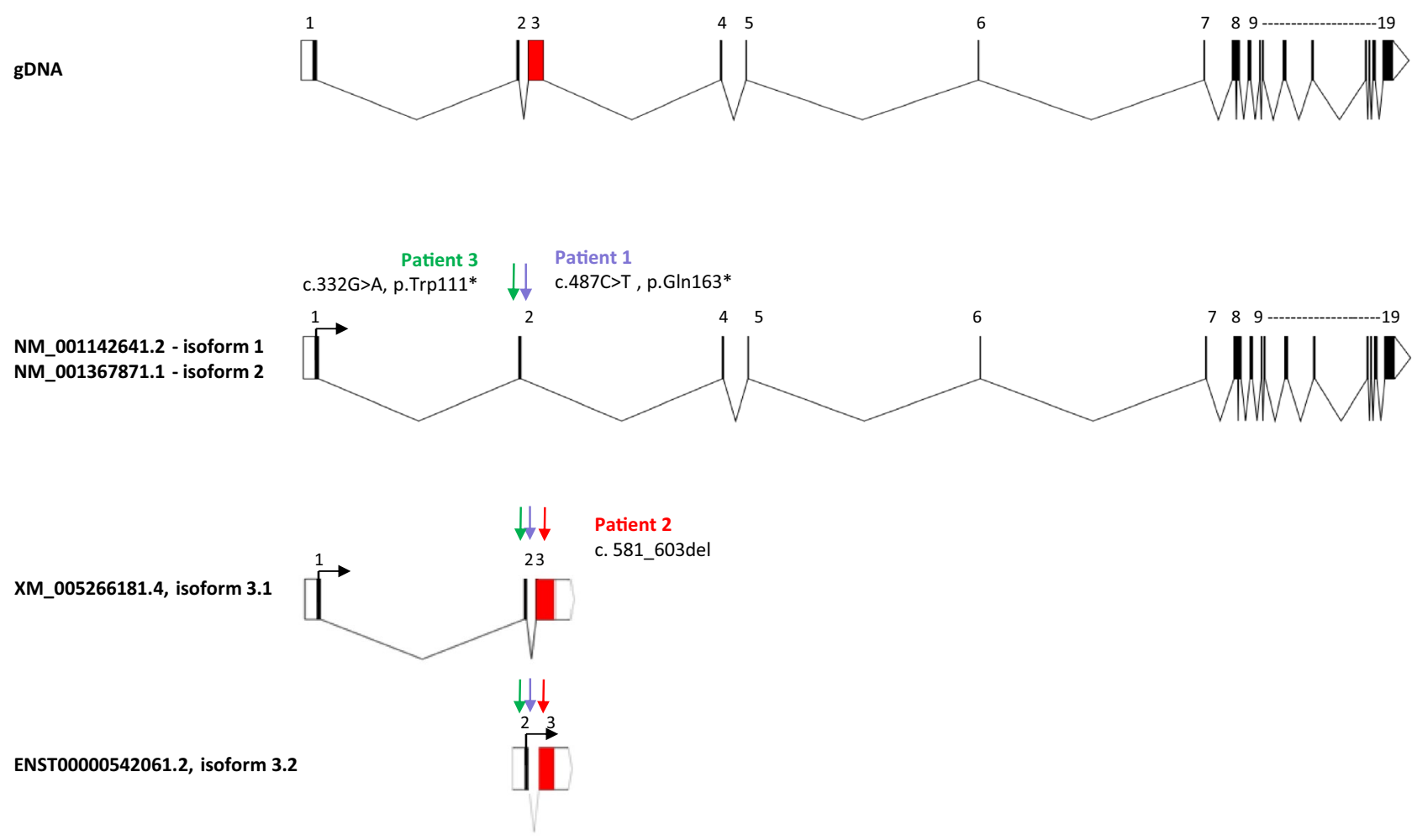

Fig. 2 Scheme of validated human FBRSL1 isoforms and localization of the detected mutations. The scheme was created using the Exon-IntronGraphic Maker available at https://wormweb.org/exonintron by Nikhil Bhatla (2012) (version 4)

confirmed the presence of the heterozygous 23-bp deletion in patient 2 (Suppl. Figure 1B and C). Thus, the detected 23-bp deletion (12:133,085,843-133,085,866; GRCh37/ hg19) affects exon 3 and can be described as c.581_603del with respect to the ATG of the transcript isoform 3.1. Isoform 3.1 encodes a hypothetical protein consisting of 589 amino acids $(\sim 66 \mathrm{kDa})$, while isoform 3.2 has an estimated molecular weight of $55 \mathrm{kDa}$. According to in silico analysis, both isoforms contain a DNA translocase domain (FtsK domain, NCBI conserved domains database, CDD) encoded by a part of exon 3 . The long isoform 1 lacks this domain and contains instead a AUTS2 (autism susceptibility gene 2) domain in the C-terminal part, describing a homologous region found in the FBRSL1 paralogue AUTS2.

Using an N-terminal antibody for Western blot analysis on protein lysates from HEK293 cells we detected an approximately $110 \mathrm{kDa}, 66 \mathrm{kDa}$ and $55 \mathrm{kDa}$ band corresponding to the estimated sizes of isoforms 1, 3.1 and 3.2. Two additional bands were observed, possibly belonging to additional isoforms. Furthermore, we were able to confirm the endogenous protein bands by expression of the respected isoforms 1, 3.1 and 3.2 in fusion to an HA-taq in HEK293 cells, using the N-terminal antibody as well as an HA-antibody (Fig. 3).
The 23-bp deletion affects only the two short transcripts 3.1. and 3.2, while isoform 1 remains unaffected. The deletion leads to a frameshift with a premature stop codon at position 356 (isoform 3.1), disrupting the DNA translocase domain (amino acid position 444-511, isoform 3.1). Interestingly, the stop mutations p.Trp $111^{*}$ and p.Gln163* detected in the other two patients impair not only isoform 1 , but also the newly validated isoforms 3.1 and 3.2. In all three cases, the DNA translocase domain is affected. We conclude that the shorter isoforms and the disruption of the DNA translocase domain are responsible for the observed recognizable phenotype.

\section{FBRSL1 is ubiquitously expressed and the different isoforms show different cellular localization}

Expression analysis was performed by RT-PCR on human fetal and adult tissues using human cDNA panels (Clontech) as well as on RNA isolated from human lymphocytes and the two human cell lines, HeLa and HEK293. For isoform 1 we observed a ubiquitous expression pattern as described in the databases (e.g. proteinatlas.org). The same observation was made for isoform 3.2, while isoform 3.1 showed a clear expression in fetal tissues, with partial lack of expression in the adult tissues (Suppl. Figure 3). 
Fig. 3 Western blot analysis of endogenous and transfected FBRSL1 isoforms. a Scheme representation of FBRSL1 isoforms detectable with an $\mathrm{N}$-terminal antibody. The scheme was created using a domain architecture software (https://prosite.expasy.org/ mydomains). Isoform 1, consisting of the AUTS2 domain, has a predicted molecular weight of $110 \mathrm{kDa}$, while isoform 3.1 has a predicted molecular weight of $66 \mathrm{kDa}$ and isoform 3.2 of $55 \mathrm{kDa}$. Isoforms 3.1. and 3.2 lack the AUTS2 domain and contain a Ftsk DNA translocase domain with an unknown function. b Plasmids containing isoforms $1,3.1$ and 3.2 in fusion to an HA-taq were detected with either an HA-antibody (HA) or with the N-terminal FBRSL1 antibody (N-terminal) in comparison to the endogenous FBRSL1 expression of HEK293 cells. The approximately estimated sizes of $110 \mathrm{kDa}, 66 \mathrm{kDa}$ and $55 \mathrm{kDa}$ of the three different isoforms were detected

A

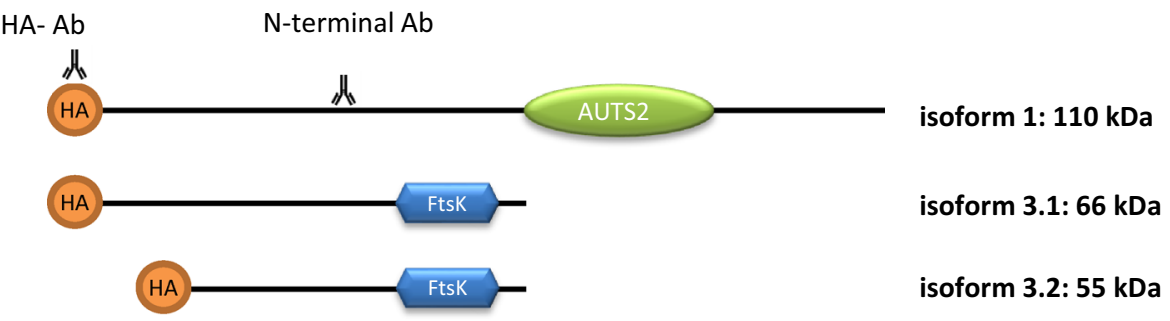

B

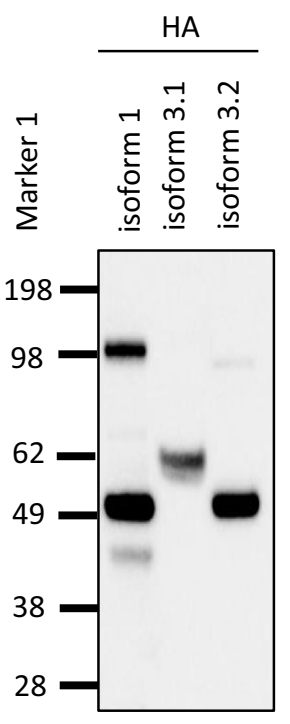

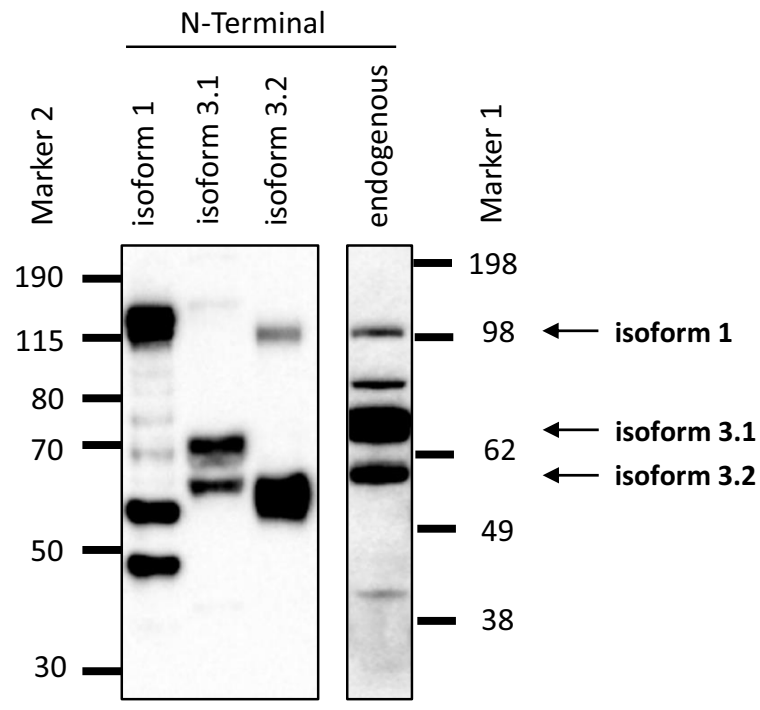

In addition, we studied the subcellular localization of FBRSL1 by immunofluorescence analysis in HEK293 cells (Fig. 4a) and human fibroblasts (Fig. 4b) by using an N-terminal and a C-terminal antibody against FBRSL1 for detection. With the C-terminal antibody, detecting full-length isoforms and potential short C-terminal isoforms, a mainly nuclear distribution was observed. With the N-terminal antibody, detecting the full-length isoform and isoforms 3.1 and 3.2, a cytoplasmic and nuclear localization was detected. In particular, N-terminal FBRSL1 isoforms appeared to be associated with the centrosomes and the kinetochores in dividing cells. We conclude therefore that FBRSL1 localizes in both nuclear and extranuclear subcellular regions depending on its isoforms.

\section{FBRSL1 knockdown in Xenopus laevis embryos results in reduction of craniofacial structures}

To explore whether the symptoms that were observed in the patients with a FBRSL1 mutation can be phenocopied in other vertebrates, we performed Fbrsl1 loss-of-function studies in Xenopus laevis (Fig. 5). Analysis of the temporal fbrsll expression pattern in Xenopus laevis revealed that fbrsll is already maternally expressed in the oocyte and throughout early embryonic development from stage 2 to 40 (Fig. 5a, b). Knockdown of Fbrs11 in Xenopus laevis embryos was achieved by injection of a fbrsll spliceblocking morpholino (fbrsll MO), blocking splicing at the exon 1 /intron 1 boundary. Blocking this first splice site resulted in intron 1 inclusion (Fig. 5a), which was confirmed by RT-PCR and sequencing of the amplified cDNA fragment (Suppl. Figure 4). As intron 1 contains several in-frame stop codons, MO injection results in a severe truncation of the Fbrsl1 protein. Interestingly, fbrsll MO injection caused a significant reduction of craniofacial structures and the eye in stage 40 Xenopus laevis embryos, whereas wild-type and control MO (co MO) injected embryos developed normally (Fig. 5c, f). As the reduction of craniofacial structures most likely results from abnormal cartilage development, we performed immunostaining of collagen II to visualize the cartilage of the head of stage 44 Xenopus laevis embryos. Collagen II staining revealed cartilage hypoplasia on the fbrsll MO injected side of the embryos (Fig. 5d, g). The Meckel's cartilage, the ceratohyal cartilage and the branchial arches were reduced, whereby the branchial arches were most severely affected. The basihyal cartilage, however, was not affected. As the patients carrying a FBRSL1 mutation developed 
A
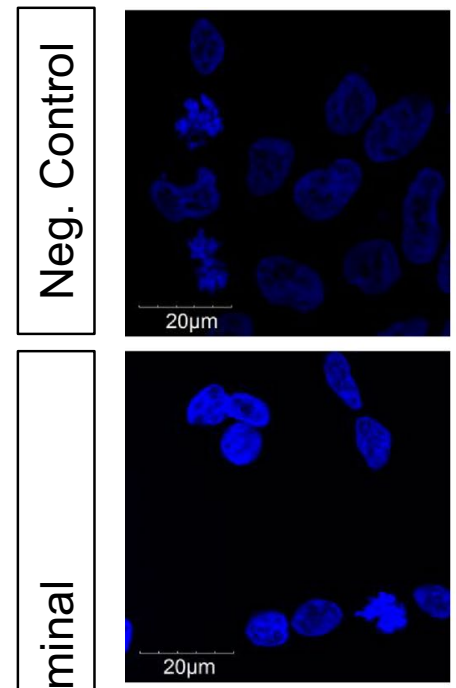

$20 \mu \mathrm{m}$

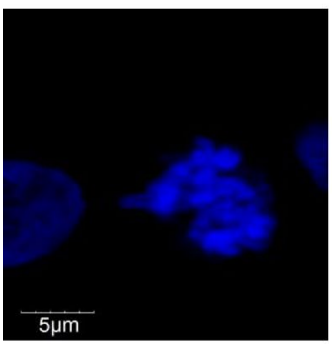

\begin{tabular}{|l|}
$\frac{\sigma}{E}$ \\
$\frac{E}{\bar{E}}$ \\
$\frac{1}{U}$ \\
\hline
\end{tabular}

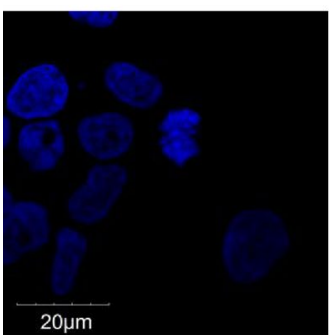

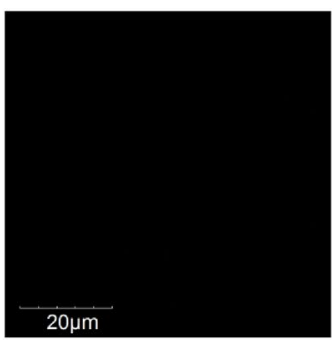
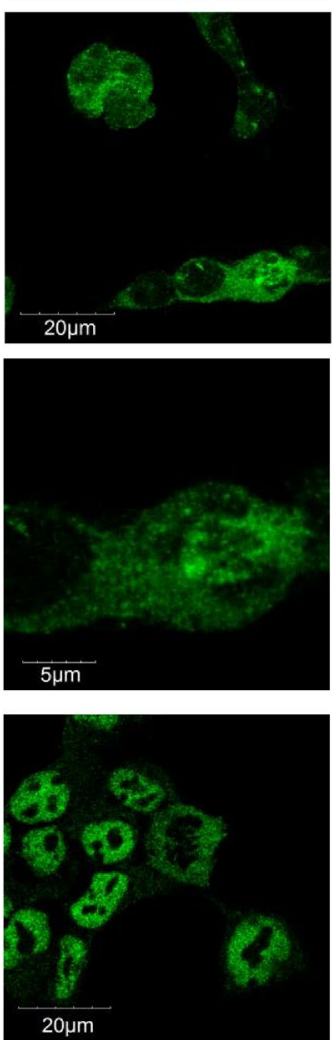
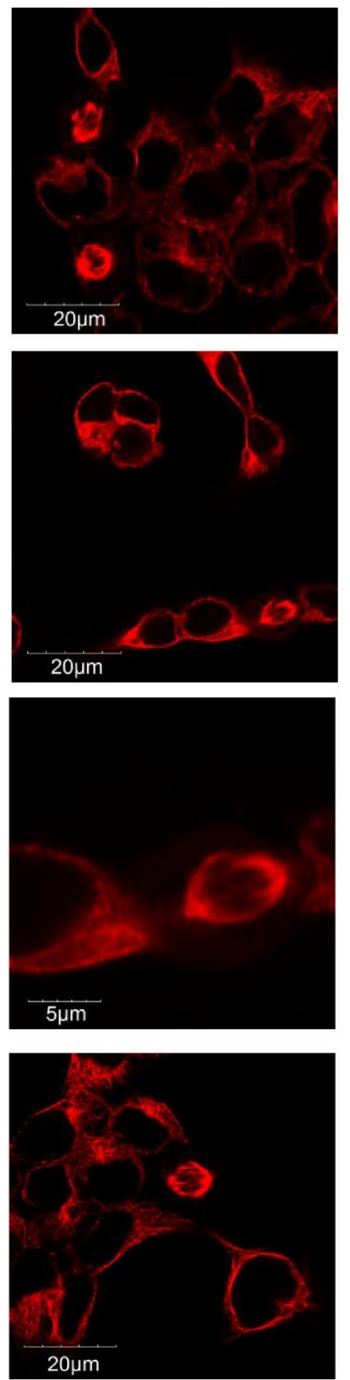
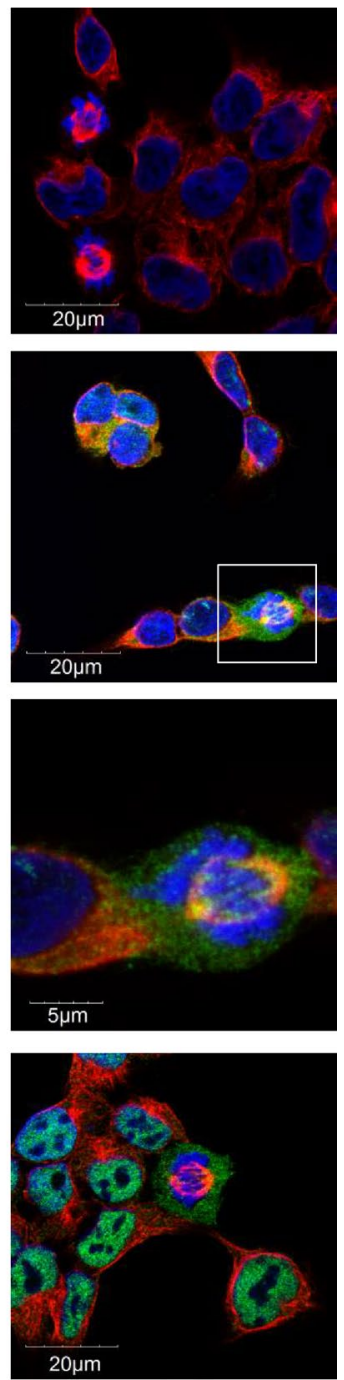

Fig. 4 Immunofluorescence analysis performed on HEK293 cells (a) and human fibroblasts (b). The N-terminal antibody detected isoforms 1, 3.1 and 3.2 in the cytoplasm and nucleus. Interestingly, an association with centrosomes (white arrow) and kinetochores was detected. Staining with a C-terminal antibody, detecting the fulllength isoform 1 and additional hypothetic short $\mathrm{C}$-terminal isoforms,

microcephaly, we analyzed the development of the brain by Ncam immunostaining in Xenopus laevis embryos. Consistent with the symptoms of the patients, Fbrsl1 depletion in Xenopus laevis leads to a strong reduction of Ncam expression indicating defects in brain development at the fbrsll MO injected side (Fig. 5e, h). Whole-mount in situ hybridization confirmed fbrsll mRNA expression in craniofacial structures including the brain, the branchial arches and the cranial nerve at stage 31 wild-type Xenopus embryos (Suppl. Figure 5). The results obtained indicate that Fbrsl1 seems to function during the development of craniofacial structures in both human and Xenopus laevis. showed a mainly nuclear pattern without a co-localization with the mitotic spindle, centrosomes or kinetochores. $\alpha$-Tubulin was used for cytoskeletal staining and nuclei were stained using DAPI. Images were obtained using a confocal laser microscope with $\times 600$ magnification, and an additional software magnification as indicated in the respectively images

\section{Fbrsl1 loss-of-function affects neuronal migration in Xenopus laevis embryos}

AUTS2 has been described to regulate neuronal migration and neuritogenesis (Hori et al. 2014; Hori and Hoshino 2017). To study whether Fbrsl1 might have similar functions, we visualized neurons using the pan-neural marker Ncam in stage 40 embryos. The cranial nerves and motor neurons on the Fbrsl1-depleted side show impaired neuronal migration, while directional neuronal migration is observed in wild-type and Co MO injected embryos. Cranial nerves grow out of the brain but fail to migrate in a directional 


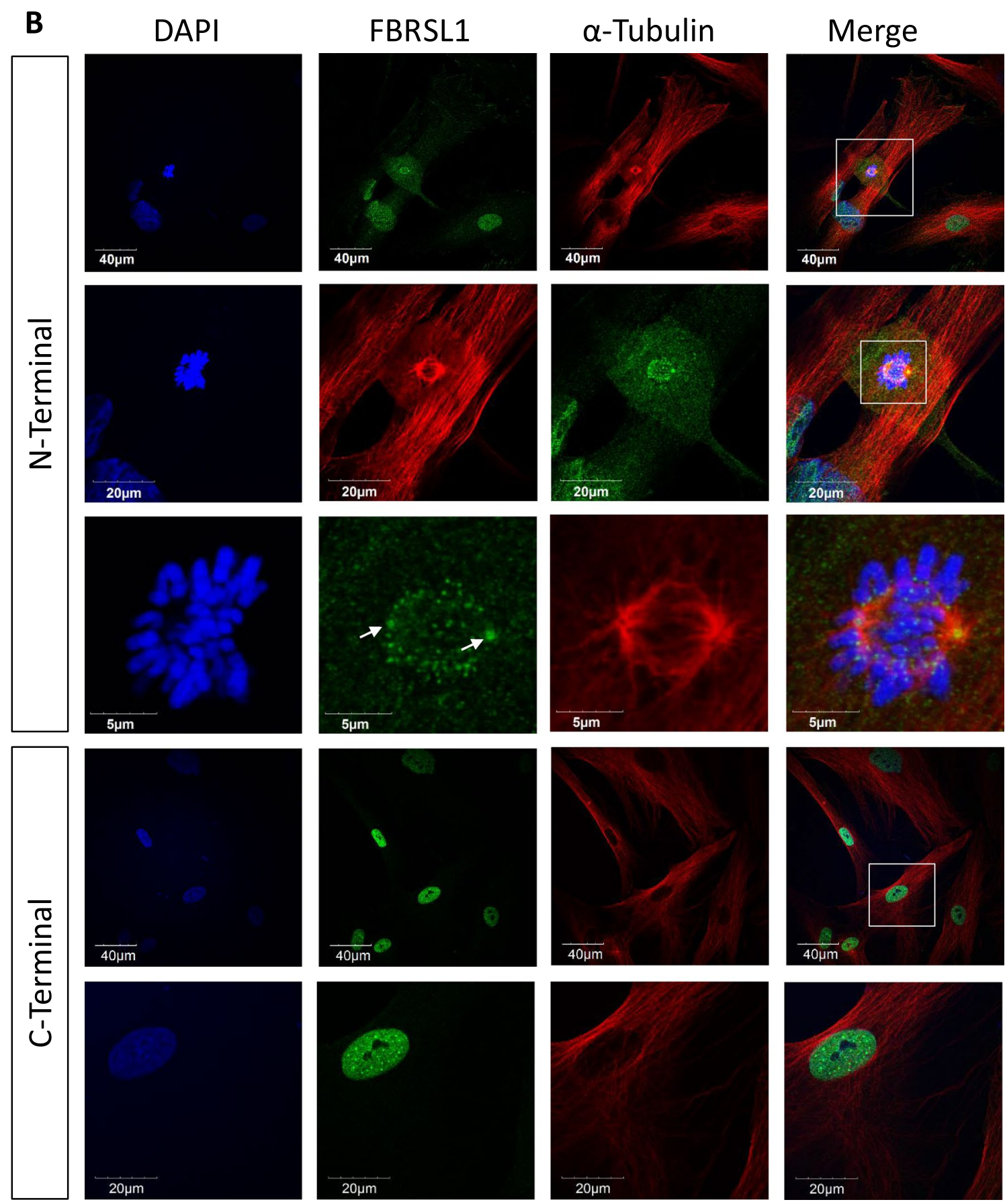

Fig. 4 (continued)

pattern to the ventral side. Similarly, the motor neurons elongate from the spinal cord, but lose their typical chevronshaped organization (Fig. 6a, b). Thus, it seems that Fbrsl1 might affect neuronal migration, as it has been shown for Auts2.
The human short $\mathrm{N}$-terminal FBRSL1 isoform rescues craniofacial defects caused by fbrsl 1 knockdown in Xenopus laevis embryos

Based on the finding that all three detected mutations in the patients affect the short N-terminal FBRSL1 isoforms 3.1 and 3.2, we hypothesized that the disruption of this shorter 
A

fbrs/1

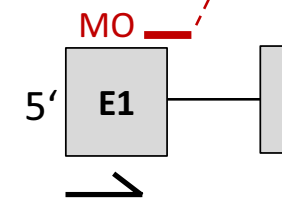

, 5

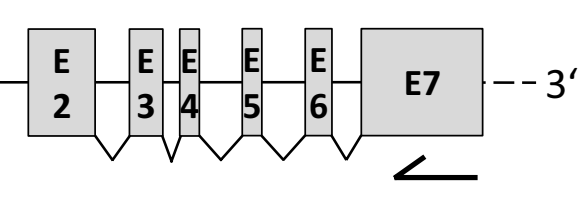

$\stackrel{\text { Splicing }}{\longrightarrow}$

B

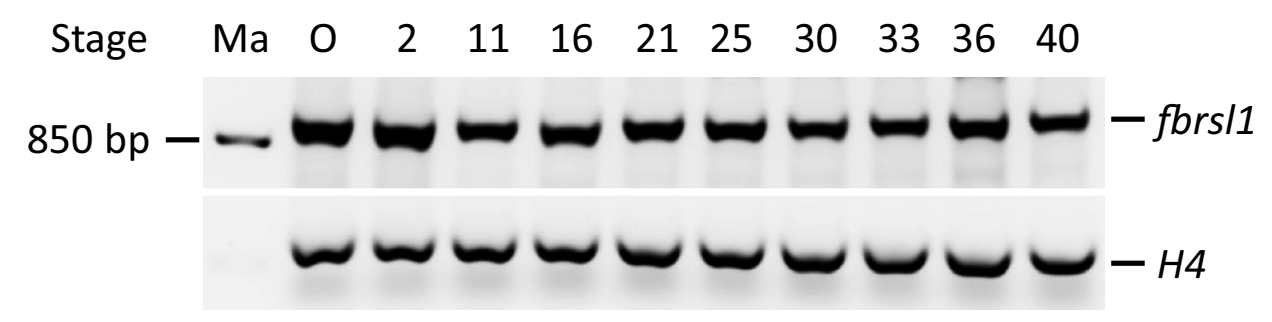

with intron 1 inclusion
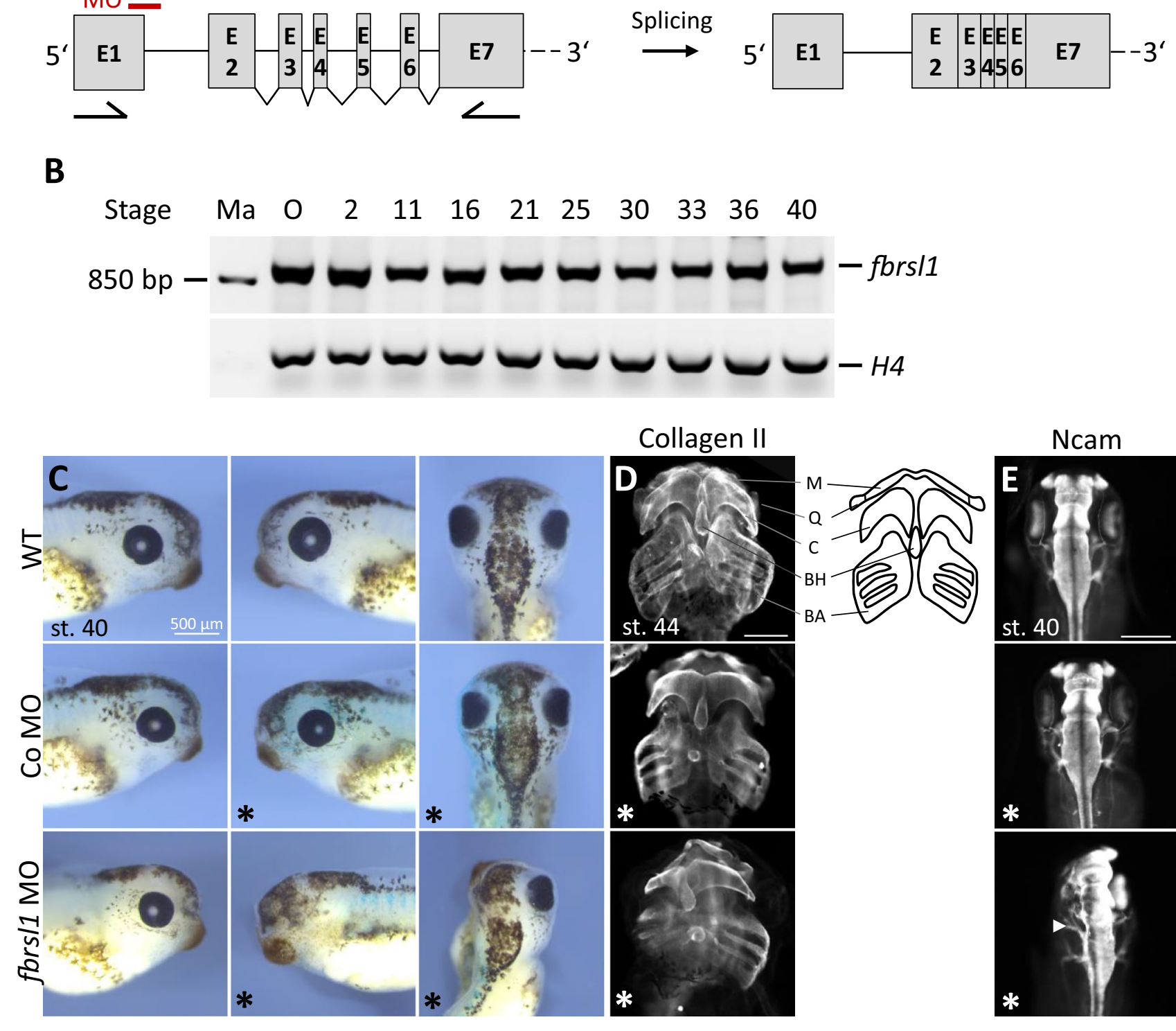

Collagen II
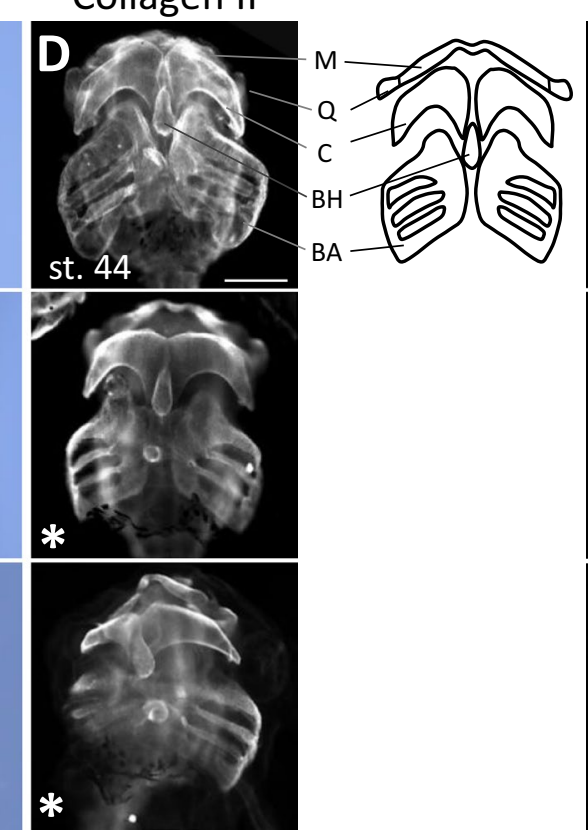

Ncam

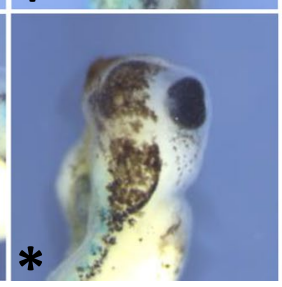

F Craniofacial defects [\%]
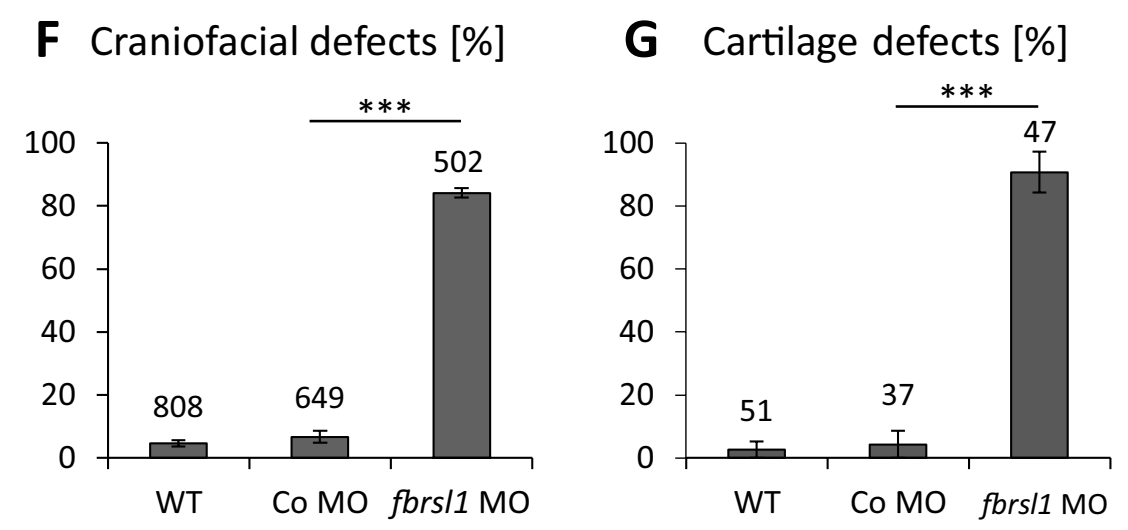

H Brain defects [\%]

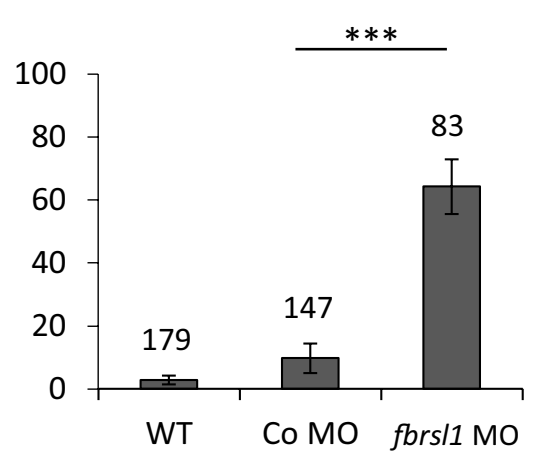


४Fig. 5 Fbrsl1 loss-of-function causes craniofacial defects in Xenopus laevis development. a Scheme of the 5' region of Xenopus laevis fbrsll with indicated exons, introns and the fbrsll E1/I1 spliceblocking Morpholino target side and possible outcome (mRNA with intron 1 inclusion) after splicing. Xenopus laevis fbrsll consists of 19 exons. The Morpholino sequence is given in the red dashed square. Arrows under exon 1 and exon 7 indicate the locations of the forward and reverse primer used for RT-PCR. b RT-PCR analysis of temporal fbrsl 1 expression in the oocyte and different developmental stages of Xenopus embryos. RT-PCR analysis of histone H4 serves as loading control. Ma: Marker, O: Oocyte. c Stage 40 wild-type and control Morpholino (10 ng) injected embryos developed normal craniofacial structures and eyes. Injection of $10 \mathrm{ng}$ fbrsll MO results in severe craniofacial defects and a reduction of the eye on the fbrsll MO injected side (marked by *). d Anti-Collagen Type II immunofluorescence staining of stage 44 Xenopus embryos showing cartilage defects in embryos injected with fbrsll MO but not in wild-type or Co MO injected embryos. M: Meckel's, Q: quadrate, C: ceratohyal, BH: basihyal, BA: branchial arches. Scale bar represents $500 \mu \mathrm{m}$. e Anti-Ncam immunofluorescence staining of stage 40 Xenopus embryos shows normal brain development in control embryos, but reduced Ncam expression in embryos injected with fbrsll MO. f, g, h The graphs summarize craniofacial, cartilage and brain defects of at least three independent experiments; number of embryos ( $n$, above each bar) and standard errors of the mean are given. $*^{* *} p<0.001$ in a Student's $t$-test and a one-way ANOVA test

isoforms and thereby of the DNA translocase domain (FtsK) is crucial for the development of the clinical symptoms. Indeed, craniofacial defects caused by Fbrsl1 knockdown in Xenopus laevis embryos were partially rescued only by co-injection of the human FBRSL1 isoform 3.1 in a dosedependent manner (Fig. 7a-c). Co-injection of $100 \mathrm{pg}$ of the FBRSL1 isoform 3.1 led to a slight but not significant rescue of craniofacial malformations. In contrast, co-injection of $200 \mathrm{pg}$ or $300 \mathrm{pg}$ of FBRSL1 isoform 3.1 resulted in a significant rescue of craniofacial defects. Co-injection of the FBRSL1 isoform 1 lacking the DNA translocase domain did not rescue the craniofacial defects caused by Fbrsll depletion (Fig. 7b, d). Interestingly, the mutated human FBRSL1 isoform 3.1-p.Gln $163 *$ containing the p.Gln $163^{*}$ mutation from patient 1 also failed to rescue the craniofacial defects caused by Fbrsl1 depletion (Fig. 7a, d). These data support the hypothesis that mutations of the shorter N-terminal isoforms are causative for the described phenotype.

\section{Discussion}

In the present study, we report three unrelated children with an hitherto undiagnosed, but recognizable malformation syndrome and a heterozygous truncating variant in FBRSL1. All children presented with respiratory insufficiency, feeding difficulties, postnatal growth restriction and microcephaly, global developmental delay, no active speech, contractures, facial dysmorphism and other malformations like heart defects, cleft palate and distinctive skin creases in the first year of life. The skin folds observed in two children affected preferentially the back and became less pronounced with increasing age.

In two children, we confirmed the FBRSL1 variant to be de novo, while in the third child the father was not available for genetic testing. No other variant explaining the symptoms was detected by exome sequencing in the three affected children. The two identified nonsense mutations and the deletion in FBRSL1 are not described in large cohorts like the Exome Aggregation Consortium (ExAC) or in the gnomAD database. All three mutations cluster in the N-terminal region of $F B R S L 1$, affecting a hypothetical transcript isoform. We were able to demonstrate the existence of this isoform by RT-PCR and Western blot analysis in addition to another hypothetical variant, using an alternative in-frame ATG in exon 2.

FBRSL1, a poorly characterized gene, is a paralogue of AUTS2. Pathogenic mutations in AUTS2, mainly gross deletions, lead to a neurodevelopmental syndrome with autism, microcephaly, short stature, contractures, facial dysmorphism and, in some cases, additional malformations like heart defects (Beunders et al. 2013), demonstrating an overlap to the phenotype observed in our three patients with truncating FBRSL1 variants. The AUTS2 syndrome phenotype can be highly variable, ranging from unaffected carriers to the full syndrome. A genotype-phenotype correlation exists. Individuals with an in-frame deletion of the $\mathrm{N}$-terminal part show a milder phenotype, restricted to variable degrees of neurocognitive defects, than individuals with a deletion affecting the $\mathrm{C}$-terminal part of the gene. The full AUTS2 syndrome phenotype is usually present in cases with an inactivation of the entire gene or the C-terminal part of the gene (Beunders et al. 2016).

For AUTS2, several isoforms have been described including a long isoform, counting 19 exons, a short C-terminal isoform starting from exon 9 , and a short $\mathrm{N}$-terminal transcript (Beunders et al. 2013; Oksenberg and Ahituv 2013; Hori and Hoshino 2017). Auts2 knockdown in zebrafish leads to morphants recapitulating part of the human phenotype including microcephaly and smaller lower-jaw size. The zebrafish phenotype was fully rescued by using the human full-length transcript and the shorter $3^{\prime}$ transcript (Beunders et al. 2013, 2016; Oksenberg et al. 2013). Both transcripts share a highly conserved AUTS2 domain, leading to the suggestion that the disruption of the AUTS2 domain is responsible for the phenotype.

We used the Xenopus laevis system for further in vivo analysis. A knockdown of Fbrsll leads to craniofacial abnormalities and disturbance in the outgrowth of cranial nerves and motor neurons in Xenopus laevis embryos. Interestingly, in contrast to the Auts 2 experiments, we were able to rescue the craniofacial defects with the short $\mathrm{N}$-terminal isoform, 

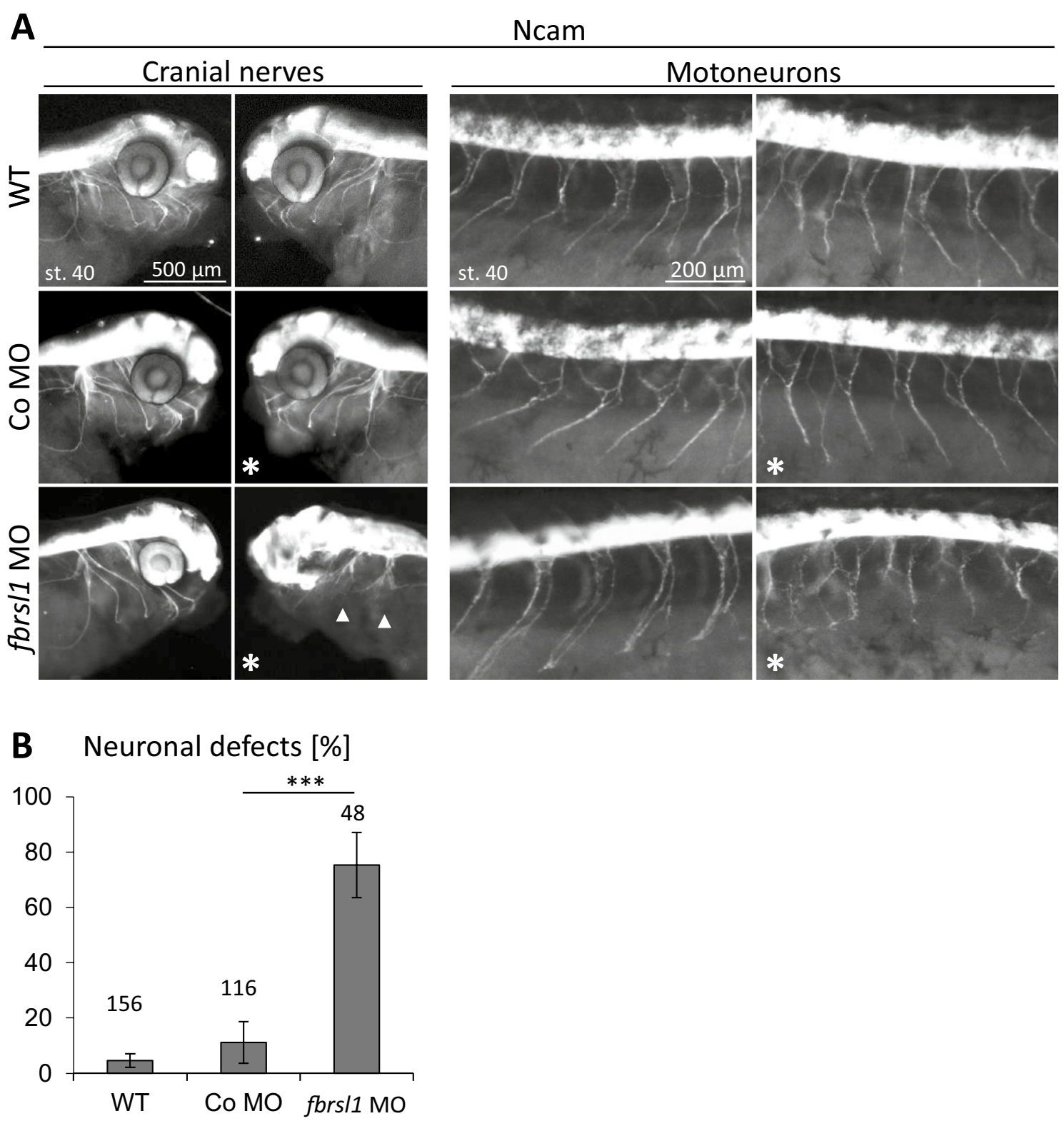

Fig. 6 Neuronal migration is disturbed in fbrsll depleted embryos. a Anti-Ncam immunofluorescence staining of stage 40 Xenopus laevis embryos indicate normal neuronal migration of cranial nerves and motor neurons in wild-type and $10 \mathrm{ng}$ Co MO injected embryos, but disturbed neuronal migration in embryos injected with $10 \mathrm{ng}$ fbrsl

while the long isoform showed no statistically significant effect. In addition, the short $\mathrm{N}$-terminal isoform bearing the mutation c. 487C > T (p.Gln163*) failed to rescue the Xenopus laevis phenotype, confirming the pathogenicity of the mutation.

In silico analysis revealed that the used short $\mathrm{N}$-terminal isoform contains a DNA translocase domain in exon 3 with unknown function. As isoform 1 lacks exon 3, this version does not contain the DNA translocase domain but contains instead in its C-terminal region the AUTS2 domain, which
MO (arrow). b The graph summarizes three independent experiments, number of embryos ( $n$, above each bar)) and standard errors of the mean are given. ${ }^{* * *} p<0.001$ in a Student's $t$-test and a one-way ANOVA test

is missing in the short $\mathrm{N}$-terminal variant. The different domain architecture of the isoforms suggests that they differ in their functional roles.

In humans, gross deletions encompassing FBRSL1 as well as neighboring genes have been reported (Decipher database). However, the phenotype of these patients, which may likely also depend on additionally affected genes, is different from our patients and for example the typical skin creases have not been reported. Moreover, isoform 1 seems to be tolerant to loss of function (LoF) mutations 

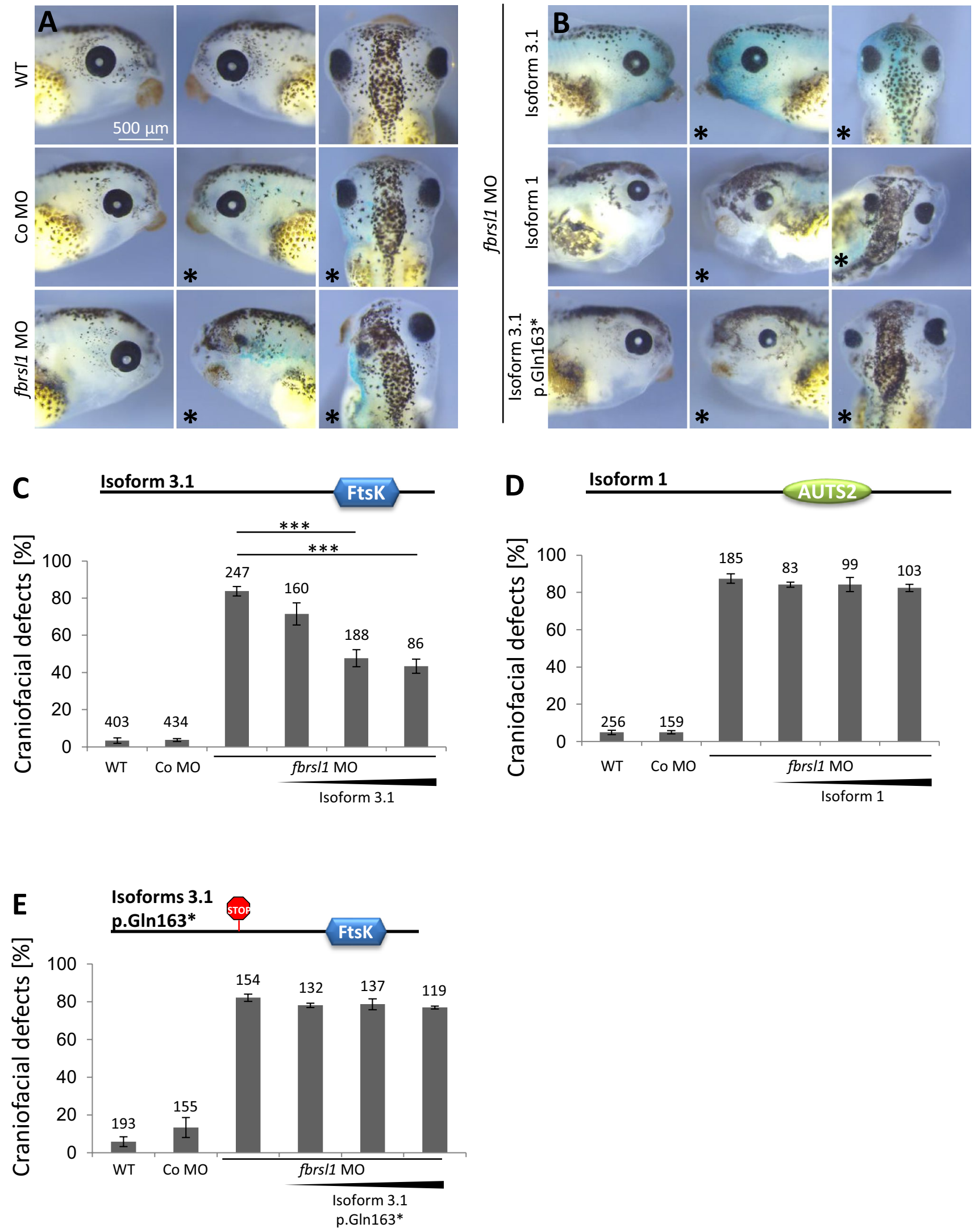
4Fig. 7 The short human N-terminal FBRSL1 isoform 3.1 can rescue craniofacial malformations induced by Fbrsl1 depletion in Xenopus laevis. a Injection of $10 \mathrm{ng}$ fbrsll MO caused a reduction of craniofacial structures and the eye, while wild-type and $10 \mathrm{ng}$ Co MO injected embryos developed normally. b-e Co-injection of the human FBRSL1 isoform 3.1 significantly rescues craniofacial malformations. In contrast, co-injection of the human FBRSL1 isoform 1 or the mutated human isoform 3.1-p.Gln163* with $10 \mathrm{ng}$ fbrsll MO does not rescue craniofacial malformations caused by Fbrsll depletion. Embryos injected with $300 \mathrm{pg}$ of the human FBRSL1 isoforms are shown in (b). c-e Graphs summarizing the percentage of craniofacial defects of at least three independent experiments after co-injection of increasing concentrations $(100,200$ and $300 \mathrm{pg})$ of the indicated human FBRSL1 isoforms with fbrsll MO. \pm s.e.m. and numbers of embryos are indicated ( $n$, above each bar). Scale bar: $500 \mu \mathrm{m}$. *** $p<0.001$ in a Student's $t$-test and one-way ANOVA with Dunnett's multiple comparisons test

( $\mathrm{pLI}=0.01$; gnomAD database); indeed there are truncating alleles listed in gnomAD for this transcript version, suggesting that truncated protein variations exist in the normal, healthy population. Thus, for the long FBRSL1 transcripts (isoform 1 and 2) haploinsufficiency appears to be unlikely.

In our three patients the two, short N-terminal, FBRSL1 transcripts are affected. Although truncating variants have been described (gnomAD) for exon 1, so far no truncating variants have been observed in the newly characterized short $\mathrm{N}$-terminal transcript using an in-frame ATG in exon 2 (isoform 3.2). Thus, the underlying disease mechanism could be due to haploinsuffiency of the isoform 3.2 and a resulting misbalance between the different FBRSL1 isoforms.

Nevertheless, as truncating alleles of all three patients escaped nonsense-mediated mRNA decay (NMD) a dominant-negative mechanism for the detected variants is also conceivable. For example, for microtubule associated proteins like $\alpha$-tubulin a dominant-negative effect was demonstrated for some variants (Aiken et al. 2019). It was suggested that multiple tubulin isotypes can partially compensate for a heterozygous deletion of a tubulin gene, but may not overcome an altered microtubule function due to dominant-negatively acting variants. The same mechanism could be possible for a gene like human FBRSL1, which has different isoforms and paralogues. Further studies are needed to clarify this aspect.

The fact that the isoforms have a different subcellular localization supports the hypothesis of different functional roles. With the C-terminal antibody, detecting full-length and possible short $\mathrm{N}$-terminal isoforms, a nuclear pattern was observed, while with the N-terminal antibody, detecting the full-length isoform and isoforms 3.1 and 3.2, a predominant cytoplasmatic localization was detected. Furthermore, the short N-terminal FBRSL1 isoforms show a co-localization with the centrosomes and the kinetochores, suggesting a role in microtubule-kinetochore organization, as well as a possible function in correct cell division. Centrosomes, the microtubule-organizing centers of the cells, are described to play an important role during embryonic CNS growth and neurogenesis by controlling appropriate cell divisions. The disturbance of this mechanism is suggested to be responsible for neurodevelopmental disorders and microcephaly (Saade et al. 2018), a symptom seen in all three patients.

Microtubules are known to be involved in different mechanisms like proper neural crest cell migration and outgrowth of neurites, nuclear translocation, chromatid separation and intracellular trafficking (Breuss and Keays 2014; Breuss et al. 2017). Skin development and stratification occur through asymmetric cell divisions in which the orientation of the mitotic spindle plays an important role (Lechler and Fuchs 2005; Williams et al. 2011). Regarding the circumferential skin folds observed in CSCSC syndrome patients, it was suggested that the underlying cause are defects in cell division leading to an altered progenitor output (Isrie et al. 2015). A disturbed microtubule-kinetochore function could explain main parts of the observed symptoms in our patients via defects in neural crest cell migration and neurite outgrowth and cell division problems.

We conclude that the disruption of the N-terminal isoforms, affected in all three patients, at critical points in embryogenesis lead to a neurodevelopmental syndrome with similarities to the CSCSC syndrome and the AUTS2 syndrome.

\section{Web resources}

DECIPHER, https://decipher.sanger.ac.uk/

ExAC Browser, https://exac.broadinstitute.org/ now included into https://gnomad.broadinstitute.org/ gnomAD Browser, https://gnomad.broadinstitute.org/

Acknowledgements Open Access funding provided by Projekt DEAL. We thank the patients and their families for participation in this study and Karin Boss for critically reading of the manuscript. We thank Barbara Kostron for extensive data base analysis and primer design for the fbrsll expression analysis and Maren Bacher for cloning of the fbrsll Xenopus in situ probe. Furthermore, we thank Silke Kaulfuss, Jessica Nolte and Peter Burfeind for their helpful discussions.

Funding This work was supported by the Deutsche Forschungsgemeinschaft (DFG, German Research Foundation) grant PA 2030/5-1 to S.P and by the Deutsche Forschungsgemeinschaft under Germany's Excellence Strategy_EXC 2067/1- 390729940 to B.W.

Data availability The raw whole-exome sequencing data of the affected children and their parents cannot be made publicly available for reasons of individual's confidentiality. All other in this study generated data are included in the article (and its supplemental data).

\section{Compliance with ethical standards}

Conflict of interest The authors declare no conflicts of interest. 
Statement of ethics Informed consent was obtained from the parents of the patients. The present study was approved by the ethics committee of the faculty of Medicine, University of Göttingen (file no 3/2/16).

Open Access This article is licensed under a Creative Commons Attribution 4.0 International License, which permits use, sharing, adaptation, distribution and reproduction in any medium or format, as long as you give appropriate credit to the original author(s) and the source, provide a link to the Creative Commons licence, and indicate if changes were made. The images or other third party material in this article are included in the article's Creative Commons licence, unless indicated otherwise in a credit line to the material. If material is not included in the article's Creative Commons licence and your intended use is not permitted by statutory regulation or exceeds the permitted use, you will need to obtain permission directly from the copyright holder. To view a copy of this licence, visit http://creativecommons.org/licenses/by/4.0/.

\section{References}

Aiken J, Buscaglia G, Aiken AS, Moore JK, Bates EA (2020) Tubulin mutations in brain development disorders: why haploinsufficiency does not explain TUBA1A tubulinopathies. Cytoskeleton (Hoboken) 77(3-4):40-54. https://doi.org/10.1002/cm.21567

Awad S, Al-Dosari MS, Al-Yacoub N, Colak D, Salih MA, Alkuraya FS, Poizat C (2013) Mutation in PHC1 implicates chromatin remodeling in primary microcephaly pathogenesis. Hum Mol Genet 22(11):2200-2213

Beunders G, Voorhoeve E, Golzio C, Pardo LM, Rosenfeld JA, Talkowski ME, Simonic I, Lionel AC, Vergult S, Pyatt RE, van de Kamp J, Nieuwint A, Weiss MM, Rizzu P, Verwer LENI, van Spaendonk RML, Shen Y, Wu B-1, Yu T, Yu Y, Chiang C, Gusella JF, Lindgren AM, Morton CC, van Binsbergen E, Bulk S, van Rossem E, Vanakker O, Armstrong R, Park S-M, Greenhalgh L, Maye U, Neill NJ, Abbott KM, Sell S, Ladda R, Farber DM, Bader PI, Cushing T, Drautz JM, Konczal L, Nash P, de Los Reyes E, Carter MT, Hopkins E, Marshall CR, Osborne LR, Gripp KW, Thrush DL, Hashimoto S, Gastier-Foster JM, Astbury C, Ylstra B, Meijers-Heijboer H, Posthuma D, Menten B, Mortier G, Scherer SW, Eichler EE, Girirajan S, Katsanis N, Groffen AJ, Sistermans EA (2013) Exonic deletions in AUTS2 cause a syndromic form of intellectual disability and suggest a critical role for the $\mathrm{C}$ terminus. Am J Hum Genet 92(2):210-220

Beunders G, de Munnik SA, Van der Aa N, Ceulemans B, Voorhoeve E, Groffen AJ, Nillesen WM, Meijers-Heijboer EJ, Frank Kooy R, Yntema HG, Sistermans EA (2015) Two male adults with pathogenic AUTS2 variants, including a two-base pair deletion, further delineate the AUTS2 syndrome. Eur J Hum Genet 23(6):803-807. https://doi.org/10.1038/ejhg.2014.173

Beunders G, van de Kamp J, Vasudevan P, Morton J, Smets K, Kleefstra T, de Munnik SA, Schuurs-Hoeijmakers J, Ceulemans B, Zollino M, Hoffjan S, Wieczorek S, So J, Mercer L, Walker T, Velsher L, Parker MJ, Magee AC, Elffers B, Kooy RF, Yntema HG, Meijers-Heijboer EJ, Sistermans EA (2016) A detailed clinical analysis of 13 patients with AUTS2 syndrome further delineates the phenotypic spectrum and underscores the behavioural phenotype. J Med Genet 53(8):523-532

Breuss M, Keays DA (2014) Microtubules and neurodevelopmental disease. The movers and the makers. Adv Exp Med Biol 800:75-96

Breuss MW, Leca I, Gstrein T, Hansen AH, Keays DA (2017) Tubulins and brain development-the origins of functional specification. Mol Cell Neurosci 84:58-67
Chittock EC, Latwiel S, Miller TCR, Müller CW (2017) Molecular architecture of polycomb repressive complexes. Biochem Soc Trans 45(1):193-205

Deevy O, Bracken AP (2019) PRC2 functions in development and congenital disorders. Development (Cambridge, England) 146(19). pii: dev181354. https://doi.org/10.1242/dev.181354

Dobin A, Davis CA, Schlesinger F, Drenkow J, Zaleski C, Jha S, Batut P, Chaisson M, Gingeras TR (2013) STAR. Ultrafast universal RNA-seq aligner. Bioinformatics 29(1):15-21

Gao Z, Zhang J, Bonasio R, Strino F, Sawai A, Parisi F, Kluger Y, Reinberg D (2012) PCGF homologs, CBX proteins, and RYBP define functionally distinct PRC1 family complexes. Mol Cell 45(3):344-356

Gao Z, Lee P, Stafford JM, von Schimmelmann M, Schaefer A, Reinberg D (2014) An AUTS2-Polycomb complex activates gene expression in the CNS. Nature 516(7531):349-354

Hori K, Hoshino M (2017) Neuronal migration and AUTS2 syndrome. Brain Sci 7(5). pii: E54. https://doi.org/10.3390/brainsci7050054

Hori K, Nagai T, Shan W, Sakamoto A, Taya S, Hashimoto R, Hayashi T, Abe M, Yamazaki M, Nakao K, Nishioka T, Sakimura K, Yamada K, Kaibuchi K, Hoshino M (2014) Cytoskeletal regulation by AUTS2 in neuronal migration and neuritogenesis. Cell Rep 9(6):2166-2179

Isrie M, Breuss M, Tian G, Hansen AH, Cristofoli F, Morandell J, Kupchinsky ZA, Sifrim A, Rodriguez-Rodriguez CM, Dapena EP, Doonanco K, Leonard N, Tinsa F, Moortgat S, Ulucan H, Koparir E, Karaca E, Katsanis N, Marton V, Vermeesch JR, Davis EE, Cowan NJ, Keays DA, van Esch H (2015) Mutations in either TUBB or MAPRE2 cause CIrcumferential skin creases kunze type. Am J Hum Genet 97(6):790-800

Lechler T, Fuchs E (2005) Asymmetric cell divisions promote stratification and differentiation of mammalian skin. Nature 437(7056):275-280

Lederer D, Grisart B, Digilio MC, Benoit V, Crespin M, Ghariani SC, Maystadt I, Dallapiccola B, Verellen-Dumoulin C (2012) Deletion of KDM6A, a histone demethylase interacting with MLL2, in three patients with Kabuki syndrome. Am J Hum Genet 90(1):119-124

Lek M, Karczewski KJ, Minikel EV, Samocha KE, Banks E, Fennell T, O'Donnell-Luria AH, Ware JS, Hill AJ, Cummings BB, Tukiainen T, Birnbaum DP, Kosmicki JA, Duncan LE, Estrada K, Zhao F, Zou J, Pierce-Hoffman E, Berghout J, Cooper DN, Deflaux N, DePristo M, Do R, Flannick J, Fromer M, Gauthier L, Goldstein J, Gupta N, Howrigan D, Kiezun A, Kurki MI, Moonshine AL, Natarajan P, Orozco L, Peloso GM, Poplin R, Rivas MA, Ruano-Rubio V, Rose SA, Ruderfer DM, Shakir K, Stenson PD, Stevens C, Thomas BP, Tiao G, Tusie-Luna MT, Weisburd B, Won H-H, Yu D, Altshuler DM, Ardissino D, Boehnke M, Danesh J, Donnelly S, Elosua R, Florez JC, Gabriel SB, Getz G, Glatt SJ, Hultman CM, Kathiresan S, Laakso M, McCarroll S, McCarthy MI, McGovern D, McPherson R, Neale BM, Palotie A, Purcell SM, Saleheen D, Scharf JM, Sklar P, Sullivan PF, Tuomilehto J, Tsuang MT, Watkins HC, Wilson JG, Daly MJ, MacArthur DG (2016) Analysis of protein-coding genetic variation in 60,706 humans. Nature 536(7616):285-291

Liao Y, Smyth GK, Shi W (2014) featureCounts. An efficient general purpose program for assigning sequence reads to genomic features. Bioinformatics 30(7):923-930

Moriyoshi K, Richards LJ, Akazawa C, O'Leary DD, Nakanishi S (1996) Labeling neural cells using adenoviral gene transfer of membrane-targeted GFP. Neuron 16(2):255-260

Müller J, Verrijzer P (2009) Biochemical mechanisms of gene regulation by polycomb group protein complexes. Curr Opin Genet Dev 19(2):150-158

Ng D, Thakker N, Corcoran CM, Donnai D, Perveen R, Schneider A, Hadley DW, Tifft C, Zhang L, Wilkie AOM, van der Smagt 
JJ, Gorlin RJ, Burgess SM, Bardwell VJ, Black GCM, Biesecker LG (2004) Oculofaciocardiodental and Lenz microphthalmia syndromes result from distinct classes of mutations in BCOR. Nat Genet 36(4):411-416

$\mathrm{Ng} \mathrm{SB}$, Bigham AW, Buckingham KJ, Hannibal MC, McMillin MJ, Gildersleeve HI, Beck AE, Tabor HK, Cooper GM, Mefford HC, Lee C, Turner EH, Smith JD, Rieder MJ, Yoshiura K-I, Matsumoto N, Ohta T, Niikawa N, Nickerson DA, Bamshad MJ, Shendure J (2010) Exome sequencing identifies MLL2 mutations as a cause of Kabuki syndrome. Nat Genet 42(9):790-793

Nieuwkoop PD, Faber J (eds) (1956) Normal Table of Xenopus laevis (Daudin). A systematical and chronological survey of the development from the fertilized egg till the end of metamorphosis. North-Holland Publ. Co, Amsterdam

Oksenberg N, Ahituv N (2013) The role of AUTS2 in neurodevelopment and human evolution. Trends Genet TIG 29(10):600-608

Oksenberg N, Stevison L, Wall JD, Ahituv N (2013) Function and regulation of AUTS2, a gene implicated in autism and human evolution. PLoS Genet 9(1):e1003221

Saade M, Blanco-Ameijeiras J, Gonzalez-Gobartt E, Martí E (2018) A centrosomal view of CNS growth. Development (Cambridge, England) 145(21). pii: dev170613. https://doi.org/10.1242/ dev. 170613

Scelfo A, Piunti A, Pasini D (2015) The controversial role of the Polycomb group proteins in transcription and cancer. How much do we not understand Polycomb proteins? FEBS J 282(9):1703-1722
Schuettengruber B, Bourbon H-M, Di Croce L, Cavalli G (2017) Genome regulation by polycomb and trithorax. 70 years and counting. Cell 171(1):34-57

Simon JA, Kingston RE (2013) Occupying chromatin. Polycomb mechanisms for getting to genomic targets, stopping transcriptional traffic, and staying put. Mol Cell 49(5):808-824

Smith WC, Harland RM (1991) Injected Xwnt-8 RNA acts early in Xenopus embryos to promote formation of a vegetal dorsalizing center. Cell 67(4):753-765

Vissers LELM, van Ravenswaaij CMA, Admiraal R, Hurst JA, de Vries BBA, Janssen IM, van der Vliet WA, Huys EHLPG, de Jong PJ, Hamel BCJ, Schoenmakers EFPM, Brunner HG, Veltman JA, van Kessel AG (2004) Mutations in a new member of the chromodomain gene family cause CHARGE syndrome. Nat Genet 36(9):955-957

Williams SE, Beronja S, Pasolli HA, Fuchs E (2011) Asymmetric cell divisions promote Notch-dependent epidermal differentiation. Nature 470(7334):353-358

Publisher's Note Springer Nature remains neutral with regard to jurisdictional claims in published maps and institutional affiliations.

\section{Affiliations}

\section{Roser Ufartes ${ }^{1} \cdot$ Hanna Berger ${ }^{2} \cdot$ Katharina Till $^{2} \cdot$ Gabriela Salinas $^{3} \cdot$ Marc Sturm $^{4}$ - Janine Altmüller ${ }^{5}$. Peter Nürnberg ${ }^{5,6} \cdot$ Holger Thiele $^{5} \cdot$ Rudolf Funke $^{7} \cdot$ Neophytos Apeshiotis $^{8} \cdot$ Hendrik Langen $^{9} \cdot$ Bernd Wollnik $^{1,10}$. Annette Borchers ${ }^{2,11}$ (i) Silke Pauli ${ }^{1}[$}

1 Institute of Human Genetics, University Medical Center Göttingen, Heinrich-Düker-Weg 12, 37073 Göttingen, Germany

2 Department of Biology, Molecular Embryology, Philipps-University Marburg, Marburg, Germany

3 NGS Integrative Genomics Core Unit, University Medical Center Göttingen, 37073 Göttingen, Germany

4 Institute of Medical Genetics and Applied Genomics, Calwerstr. 7, 72076 Tübingen, Germany

5 Cologne Center for Genomics (CCG), University of Cologne, Weyertal 115b, 50931 Cologne, Germany

6 Center for Molecular Medicine Cologne (CMMC), University of Cologne, Robert-Koch Str. 21, 50931 Cologne, Germany
7 Department of Neuropediatrics, Sozialpädiatrisches Zentrum, Mönchebergstr. 41-43, 34125 Kassel, Germany

8 Praxis für Humangenetik, Georg-Eckert-Straße 12, 38100 Brunswick, Germany

9 Department of Neuropediatrics, Sozialpädiatrisches Zentrum Hannover, Janusz-Korczak-Allee 8, 30173 Hannover, Germany

10 Cluster of Excellence "Multiscale Bioimaging: From Molecular Machines To Networks of Excitable Cells" (MBExC), University of Göttingen, 37073 Göttingen, Germany

11 DFG Research Training Group, Membrane Plasticity in Tissue Development and Remodeling, GRK 2213, Philipps-University Marburg, Marburg, Germany 